\title{
Dentine Hypersensitivity and Its Associated Factors: A Cross-Sectional Study Conducted on Patients Visiting Dental Hospital of Karachi, Pakistan
}

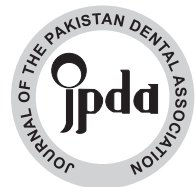

\author{
Beenish Fatima Alam ${ }^{1}$ \\ BDS, MSc, MFDS RCSEd \\ Umaima Khan ${ }^{2}$ \\ BDS \\ Nabeela Abbasi ${ }^{3}$ \\ BDS, MSc \\ Talha Nayab ${ }^{4}$ \\ BDS, MSc
}

OBJECTIVE: The aim of the study was to assess the frequency and to analyze different factors associated with dentine hypersensitivity among the patients visiting the dental outpatient department of Bahria University medical and dental college Karachi.

METHODOLOGY: A Cross sectional questionnaire based study was conducted over a period of seven months among 366 patients visiting the dental OPD of Bahria University Medical and Dental College. Survey utilized for this study was adopted from the study conducted by Braimoh and Ilochonwu. All participants answered questions related to knowledge regarding dentine hypersensitivity, factors hurting the teeth, measures taken to reduce the pain and teeth commonly affected. Statistical analysis was done using Chi-square test and descriptive statistics.

RESULTS: The frequency of DH was 36\% among the surveyed respondents. DH was considerably higher in females as compared to males. A total of $36.6 \%$ males and $50.8 \%$ females had awareness regarding DH. While $19 \%$ male and $17 \%$ female patients chewed from one side of mouth. Vigorous brushing of teeth was noted in $16 \%$ males whereas brushing for longer duration was identified in $15.3 \%$ of females. Maxillary posteriors were most sensitive teeth.

CONCLUSION: The frequency of DH among the patients was $36.3 \%$ with a predilection for females gender. Cold foods were commonly identified factors for causing sensitivity in teeth.

KEY WORDS: Dentine hypersensitivity, Dental patients, Frequency, Cross sectional study.

HOW TO CITE: Alam BF, Khan U, Abbasi N, Nayab T. Dentine hypersensitivity and its associated factors: a cross-sectional study conducted on patients visiting dental hospital of karachi, pakistan. J Pak Dent Assoc 2019;28(2):63-67.

DOI: https://doi.org/10.25301/JPDA.282.63

Received: 07 February 2019, Accepted: 06 March 2019

\section{INTRODUCTION}

$\mathrm{D}$ entine hypersensitivity (DH) is a frequent dental complaint noted in adult population. ${ }^{1}$ It can be defined as a sharp pain of short duration initiating from dentine which occurs when exposed to the external stimuli such as heat, cold, touch or chemical. ${ }^{2}$ The occurrence of dentine hypersensitivity increases from 30-40 years of age. Additionally, females are more commonly affected as compare to males. ${ }^{3,4}$ The main causes of dentin hypersensitivity are vigorous brushing, intake of citric food, and grinding of teeth due to stress. ${ }^{5}$ Countless surveys have

1. Assistant Professor, Department of Oral Biology, Bahria University Medical and Dental College.

2 .Lecturer, Department of Oral Biology, Bahria University Medical and Dental College.

3. Assistant Professor, Head of Department Oral Biology, Rawal Institute of Health Sciences.

4. Assistant Professor, Department of Dental Materials, Jinnah Sindh Medical University.

Corresponding author: "Dr. Beenish Fatima Alam " < nish_alam@yahoo.com > revealed that the exposure of root surfaces and recession of gingival tissue permits extra fast exposure of dentinal tubules as the thin layer of cementum covering the root gets detached effortlessly and causes sensitivity. ${ }^{6}$ Cold and hot stimulus are the most common stimuli, whereas dietary acid has important role in evoking Dentine Hypersensitivity. ${ }^{7}$

Three main theories of dentin hypersensitivity have been suggested: The first theory; Direct Innervation Theory, stated that the nerve's endings penetrates the dentine and extends to pulp and mechanical stimulation initiates the pain, but there is lack of proof to verify this theory. ${ }^{8,9}$ Second acclaimed theory is the Odontoblast Receptor theory, in this odontoblasts works as pain receptors and sends pain signals to pulpal nerve endings. However this theory has also been discarded as the nerve impulses are not produced and doesn't get stimulated by the cellular matrix of odontoblasts. Third theory is the Hydrodynamic Theory which is commonly accepted theory. It describes the fluid movement within the 
tubules of dentine. Dentine Hypersensitivity occurs due to the fluid movement within the tubules of dentine. This fluid movement excites baroreceptor and causes neural discharge $.9,10$

The number of dentinal tubules within the sensitive dentine are eight times more than normal and are broader in size as compared to non-sensitive dentine. ${ }^{11}$ The fluid movement within the tubules excites the nerve endings directly, either inside of the tubules or on the outer pulpal tissue, or whether the odontoblasts participate in transduction mechanism. ${ }^{12}$

Globally the prevalence of dentine hypersensitivity has been reported to be $12.3 \%$ in USA. ${ }^{13}$ It was significantly higher in UAE and Hong Kong being 27\% and 68\% respectively. ${ }^{14,15}$ Furthermore locally conducted studies carried out in Lahore have revealed that $22 \%$ patients reported the presence of DH, while another study conducted in Karachi revealed considerable increased prevalence of $36.4 \% .^{16,17}$

Limited data is available in Pakistan regarding the awareness of general population concerning the dentine hypersensitivity. Hence the main objective of our study was to assess the frequency and to analyze different factors associated with dentine hypersensitivity among the patients visiting the dental outpatient department of Bahria University Medical and Dental College in Karachi.

\section{METHODOLOGY}

This cross- sectional study was carried out over period of seven months among patients visiting dental outpatient department of Bahria University Medical and Dental College. A total of 370 questionnaires were distributed to patients out of which, 366 filled forms and 4 unfilled forms were received. Formal Approval of the study was obtained from the Ethical Review Committee of Bahria University Medical and Dental College before initiating the study (ERC 06/2019). Healthy adult patients having at least 20 natural teeth were included in the study, while patients who did not give consent for study and those having widespread periodontal problems, or having severe systemic disease such as diabetes were excluded from the study.

The objective of the research project was explained to patients before asking them to fill the questionnaires. Written consent was obtained before initiating the study. The survey required five to seven minutes to complete. Survey utilized for this study was adopted and modified from the study conducted by Braimoh and Ilochonwu. ${ }^{18}$ The preliminary part of the survey included patient's details such as age and gender. The subsequent portion of the survey concentrated on the queries related to presence of dentine hypersensitivity, awareness regarding dentine hypersensitivity, factors hurting the teeth, knowledge about factors causing it, measures taken to reduce the pain and teeth commonly affected by sensitivity. Sample size was calculated using OpenEpiTM 3. Entered data was analyzed using SPSS (v20). Descriptive statistics was applied to calculate the frequency and percentages. The responses were then cross tabulated and test of significance was done using Chi-square statistics. A p-value less than 0.05 was considered to be significant.

\section{RESULTS}

A total of 366 participants were questioned regarding presence of dentine hypersensitivity, among which $29 \%$ $(n=107)$ males and $43 \%(n=159)$ females had complains of sensitivity in teeth (Table 1).The knowledge regarding

Table 1: Frequency of Dentine Hypersensitivity among the respondents

\begin{tabular}{lcl}
\hline Dentine Hypersensitivity & Male n (\%) & Female n(\%) \\
\hline Present & $107(29.2)$ & $159(43.4)$ \\
Absent & $27(7.4)$ & $6(1.6)$ \\
Occasionally & $34(9.3)$ & $27(7.4)$ \\
Rare & $6(1.6)$ & $0(0)$ \\
Total n (\%) & $174(47.5)$ & $192(52.5)$ \\
\hline
\end{tabular}

Table 2: Responses generated by the respondents

\begin{tabular}{|l|l|l|l|}
\hline Actions Taken by respondents & Males $\boldsymbol{n}(\%)$ & Females $\boldsymbol{n}(\%)$ & p value \\
\hline Drinking with straw & $5(1.4)$ & $16(4.4)$ & \\
Chew on one side & $70(19.1)$ & $63(17.2)$ & \\
Avoid certain food & $42(11.5$ & $42(11.5)$ & \\
Wait for food to cool down & $20(5.5)$ & $20(5.5)$ & 0.000 \\
Avoid brushing painful area & $21(5.7)$ & $10(2.7)$ & \\
Cover up mouth on cold days & $0(0)$ & $23(6.3)$ & \\
No Action taken & $16(4.4)$ & $18(4.9)$ & \\
\hline Habits noted by respondents & & & \\
\hline Brushing vigorously & $59(16.1)$ & $35(9.6)$ & \\
Brush with hard bristle & $18(4.9)$ & $5(1.4)$ & \\
Brush after eating/drinking & $12(3.3)$ & $18(4.9)$ & 0.000 \\
Brushing for more than 2-3mins & $35(9.6)$ & $56(15.3)$ & \\
Grind teeth & $17(4.6)$ & $7(1.9)$ & \\
\hline Preferred Toothpaste & & & \\
\hline Fluoridated toothpaste & $61(16.7)$ & $53(14.5)$ & \\
Desensitizing toothpaste & $81(22.1)$ & $104(28.4)$ & 0.000 \\
Herbal toothpaste & $16(4.4)$ & $35(9.6)$ & \\
Smokers toothpaste & $16(4.4)$ & $0(0)$ & \\
\hline
\end{tabular}

awareness of dentine hypersensitivity was noted in $36.6 \%$ $(n=134)$ males and $50.8 \%(n=186)$ females. 
Nineteen percent $(n=70)$ male and $17 \%(n=63)$ female respondents preferred eating from one side of mouth whereas $11.5 \%(n=42)$ males and females avoided eating certain foods to avoid the feeling of discomfort (Table 2). Majority of individuals (40\%) identified ice cream as significant factor in causing tooth sensitivity followed by iced water (Figure 2).

Vigorous brushing of teeth was identified in $16 \%(n=59)$ males while brushing for longer duration i.e. 2-3 minutes was noted as major factor in $15.3 \%(n=56)$ females. The Desensitizing toothpaste was most preferred option for preventing Dentine hypersensitivity(Table 2). Teeth commonly identified to be sensitive in males and female were maxillary posterior teeth, followed by maxillary anterior teeth (Figure 1).

Figure 1:Teeth Noted to be most sensitive by the respondents
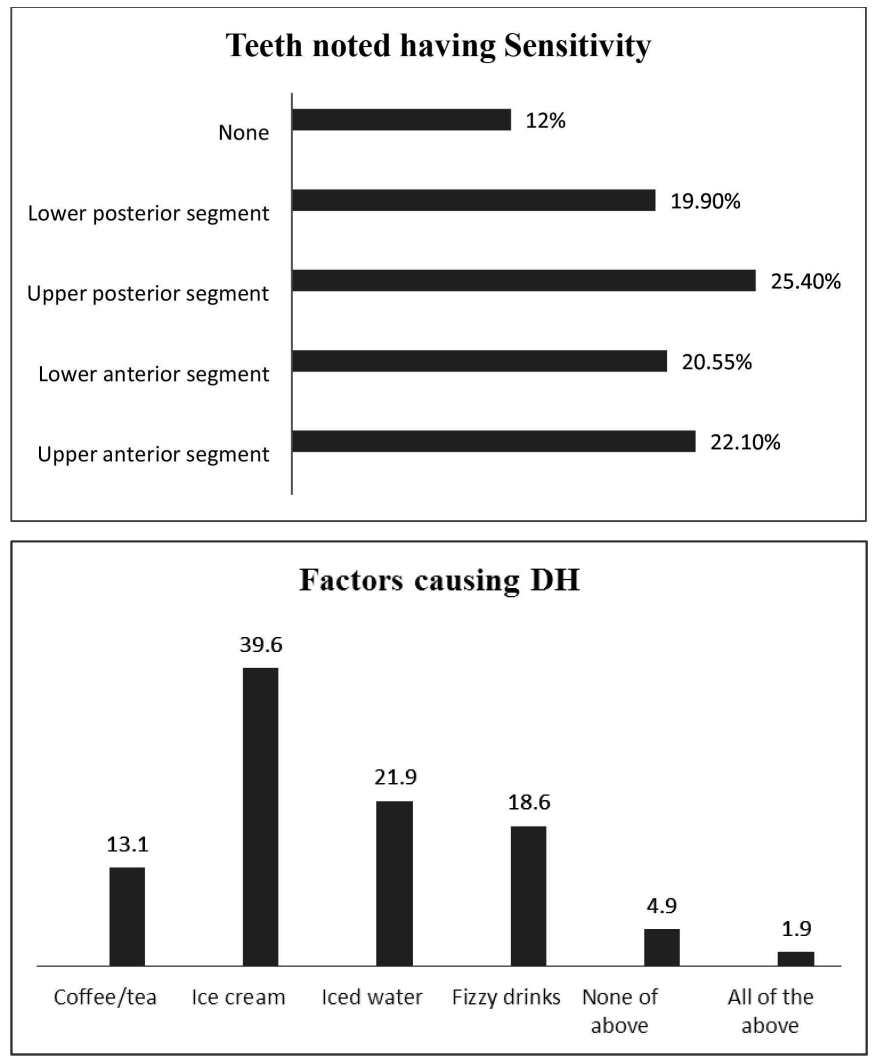

Figure 2: Factors responsible for causing DH identified by the respondents

\section{DISCUSSION}

Globally the prevalence of dentine hypersensitivity varies from $1.34 \%$ to $74 \% .{ }^{19-21}$ In the current study frequency of DH has been reported to be $36.3 \%$ which is similar to study conducted in China. ${ }^{22}$ Additionally studies carried out in Nigeria and India have revealed higher rates of $\mathrm{DH}$ about
$52.5 \%$ and $55 \%$ respectively. ${ }^{23,24}$ This difference can be attributed to different methods employed for determining $\mathrm{DH}$, such as using questionnaire alone or using it in combination with clinical examination, and also due to lack of patient knowledge and relating pain due to other causes with $\mathrm{DH}$.

In the previously conducted studies DH has been commonly identified among females. ${ }^{25,26}$ Likewise in the current study statistically significant association was noted among genders with females being more susceptible than males, it can be due to fact that women have more awareness regarding oral hygiene and frequently visits the dentist. ${ }^{27}$

Cold foods and frizzy drinks are well known risk factors for causing sensitivity in teeth. Likewise in our study almost $53 \%$ of the individuals had sensitivity on eating cold foods, these results are consistent with the study conducted by Çolak et al, Bamise et al and Gillam et al. 28,29,30

Majority of males and females respondents preferred using one side of the mouth for eating; these adaptive changes helped overcome the feeling of discomfort felt. These findings were comparable to survey conducted by Kielbassa, who reported that about three fourth of the individuals avoided using affected side of the mouth. ${ }^{31}$

Usage of hard bristle toothbrush and improper brushing technique are accountable for causing sensitivity and gingival abrasion in teeth. ${ }^{32,33}$ Studies conducted by Kassab and Cohen, Drisko $\mathrm{C}$ have identified brushing time and method as causative factors for causing gingival recession. ${ }^{34,35}$ Similarly in the current study, majority of the male patients brushed teeth forcefully while females' participants brushed their teeth for longer duration which in turn causes DH. These finding are consistent with study conducted by Levitch et al, who stated that individuals who brushed their teeth for a longer duration and used forceful brushing methods are more likely to be predisposed to $\mathrm{DH}^{36}$

Teeth most likely to be susceptible to DH were maxillary premolars and molars followed by maxillary anterior teeth. These findings are in accord with the survey carried out by Deogade et al and Ye et al. ${ }^{37,38}$ Moreover findings of our study contrasted with Taani and Awartani who identified anterior teeth to be commonly affected. ${ }^{39}$

Regarding the management of DH majority of the respondents preferred using desensitizing toothpaste. This is in accordance with survey carried out by Rao et al who stated that desensitizing agents plays key role in providing protection against sensitivity as they occlude the dentinal tubules with the help of mineral formation. ${ }^{40}$

Limitations that can be highlighted are limited sample size as it was a single center based study. Secondly it was a questionnaire based study which was conducted without performing any clinical investigations and relied solely upon 
patient's perceptions regarding the diagnosis of this condition. Hence it is quite possible for patients to relate pain due to other causes with $\mathrm{DH}$.

\section{CONCLUSION}

In the current study frequency of dentine hypersensitivity among the patients was $36.3 \%$ which is comparable to previously conducted studies. Females complained more frequently regarding the sensitivity as compared to males. Cold food was identified as risk factors for initiating sensitivity in teeth. Maxillary premolars and molars were significantly more affected by sensitivity.

\section{RECOMMENDATIONS}

Our study highlights the need for conducting multi center research regarding dentine hypersensitivity across Pakistan, which will be beneficial in providing more knowledge, awareness and data regarding $\mathrm{DH}$.

\section{CONFLICT OF INTEREST}

None declared

\section{REFERENCES}

1. Idon PI, Esan TA, Bamise CT, Mohammed ASA, Mohammed A and Ofuonye ILN. Dentine Hypersensitivity: Review of a Common Oral Health Problem. J Dent Craniofac Res, 2017;2:2-16.

2. Ana CM, Luis FL-M. Dentine sensitivity risk factors: A case-control study. Eur J Dent, 2016;10:1-6.

https://doi.org/10.4103/1305-7456.175678

3. Rahiotis C, Polychronopoulou A, Tsiklakis K, Kakaboura A. Cervical dentin hypersensitivity: A cross-sectional investigation in Athens, Greece. J Oral Rehabil, 2013;40:948-57.

https://doi.org/10.1111/joor.12109

4. Costa RS, Rios FS, Moura MS, Jardim JJ, Maltz M, Haas AN. Prevalence and risk indicators of dentin hypersensitivity in adult and elderly populations from Porto Alegre, Brazil. J Periodontol, 2014:85:1247-258

https://doi.org/10.1902/jop.2014.130728

5. Gillam. DG. Management of Dentin Hypersensitivity. Curr Oral Health Rep, 2015;2:87-94.

https://doi.org/10.1007/s40496-015-0047-x

6. Kamal.H, Abu Hantash RO, Taani DQ, Hammad MM. The Prevalence of Dentine Hypersensitivity and Gingival Recession among Jordanian Patients at JUST Dental Teaching center. J Stomatol 2014;4:497-506

https://doi.org/10.4236/ojst.2014.411067
7. Nazir MA, Almas K, Majeed MI, Majeed A, Ahmed SZ. A cross sectional study of dentin hypersensitivity among dental students and interns. J Int Dent Med Res 2018;11:376-82

8. Çolak H, Aylikçi BU, Hamidi MM, Uzgur R.Prevalence of dentine hypersensitivity among university students in Turkey. Niger J Clin Pract 2012;1541:5-9

9. Chu CH, Lo ECM. Dentin hypersensitivity: a review. Hong Kong Dent J 2010;7:15-22

10. Albashaireh AS, Aljamal M. Prevalence and pattern of dentine hypersensitivity in a Jordanian population in irbid city. Oral hyg health 2014;2:2332-0702

11. Erdemir U, Saygi G, Yucel T, and Yildiz E. Dentin Hypersensitivity and Recent Developments in Treatment Options: A Mini Review. J Sci Med Dent 2016;4:1072.

12. West NX, Lussi A, Seong J and Hellwig E. Dentin hypersensitivity: pain mechanisms and aetiology of exposed cervical dentin. Clin oral investig, 2013;17:9-19

https://doi.org/10.1007/s00784-012-0887-x

13. Cunha-Cruz J, Wataha JC, Heaton LJ et al. The prevalence of dentin hypersensitivity in general dental practices in the northwest United States. J Am Dent Assoc, 2013;144:288-96. https://doi.org/10.14219/jada.archive.2013.0116

14. Al-Khafaji H. Observations on dentine hypersensitivity in general dental practices in the United Arab Emirates. Eur J Dent 2013;7:389-94. https://doi.org/10.4103/1305-7456.120634

15. Ye W, Feng XP, Li R. The prevalence of dentine hypersensitivity in Chinese adults. J Oral Rehabil, 2012;39:182-87. https://doi.org/10.1111/j.1365-2842.2011.02248.x

16. Bajwa SJ, Qasim M, Mahmood A. the impact of dentine hypersensitivity on patient's quality of life as perceived by dentists. Pak Orthod J 2017;9:98-102

17. Akber A, Ali NS, Shabbir S et al. Frequency of DH. A crosssectional study. Pak oral dent J 2016;36:440-43.

18. Braimoh OB, Ilochonwu.NA. Dentin hypersensitivity among undergraduates in a university community. Saudi J Oral Sci, 2014;1:90-3. https://doi.org/10.4103/1658-6816.138473

19. Zappa U. Self-applied treatments in the management of dentine hypersensitivity. Arch Oral Biol 1994; 39:107-12. https://doi.org/10.1016/0003-9969(94)90196-1

20. Amarasena N, Spencer J, Ou Y, Brennan D. Dentine hypersensitivity in a private practice patient population in Australia. J Oral Rehabil. 2011; 38:52-60.

https://doi.org/10.1111/j.1365-2842.2010.02132.x

21. Tan CS, Hu DY, Fan X, Li X, Que KH. Epidemiological survey of dentine hypersensitivity of young people in Chengdu City. Hua Xi Kou Qiang Yi Xue Za Zhi 2009;27:394-96. 
22. Wang Y, Que K, Lin L, Hu D\& Li X. The prevalence of dentine hypersensitivity in the general population in China. J Oral Rehabil 2012;39:812-20.

https://doi.org/10.1111/j.1365-2842.2012.02334.x

23. Udoye CI. Pattern and distribution of cervical dentine hypersensitivity in a Nigerian tertiary hospital. Odontostomatol Trop 2006;29:19-22.

24. Vijaya V, Sanjay V, Varghese RK, Ravuri R, Agarwal A. Association of Dentine Hypersensitivity with Different Risk Factors - A Cross Sectional Study. J Int Oral Health 2013;5:88-92.

25. Dababneh RH, Khouri AT, Addy M. Dentine hypersensitivity - an enigma? A review of terminology, mechanisms, aetiology and management. Br Dent J 1999;187:606-11

26. Afolabi AO, Olojede AC, Aregbesola SB, Ogundipe OK. Prevalence and perception of self reported dentine hypersensivity among dentate populations in South-western Nigeria. Tanz Dent J 2010;16:29-34. https://doi.org/10.4314/tdj.v16i1.62037

27. Chrysanthakopoulos N.A. Prevalence of Dentine Hypersensitivity in a General Dental Practice in Greece. J Clin Exp Dent. 2011;3:e44551.

https://doi.org/10.4317/jced.3.e445

28. Çolak H, Aylikçi BU, Hamidi MM, Uzgur R. Prevalence of dentine hypersensitivity among university students in Turkey. Niger J Clin Pract 2012;15:415-19.

https://doi.org/10.4103/1119-3077.104514

29. Bamise CT, Kolawole KA, Oloyede EO, Esan TA. Tooth sensitivity experience among residential university students. Int J Dent Hyg 2010;8:95-100.

https://doi.org/10.1111/j.1601-5037.2009.00385.x

30. Gillam DG, Seo HS, Newman HN, Bulman JS. Comparison of dentine hypersensitivity in selected occidental and oriental populations. J Oral Rehabil 2001;28:20-5.

https://doi.org/10.1046/j.1365-2842.2001.00631.x

31. Kielbassa A. Dentine hypersensitivity: Simple steps for everyday diagnosis and management. Int Dent J 2002;52:386-96. https://doi.org/10.1002/j.1875-595X.2002.tb00939.x

32. Bamise CT, Olusile AO, Oginni AO. An Analysis of the Etiological and Predisposing Factors Related to Dentin Hypersensitivity. J Contemp Dent Pract 2008;5:52-9.

33. Haneet RK and Vandana LK. Prevalence of dentinal hypersensitivity and study of associated factors: a cross-sectional study based on the general dental population of Davangere, Karnataka, India. Int Dent J 2016;66:49-57.

https://doi.org/10.1111/idj.12206

34. Drisko C. Oral hygiene and periodontal considerations in preventing and managing dentine hypersensitivity. Int Dent J, 2007:57: S399-S410 https://doi.org/10.1111/j.1875-595X.2007.tb00167.x

35. Kassab MM, Cohen RE. The etiology and prevalence of gingival recession. J Am Dent Assoc, 2003;134:220-25.

https://doi.org/10.14219/jada.archive.2003.0137

36. Levitch LC, Bader JD, Shugars DA, Heymann HO. Non carious cervical lesions. J Dent 1994;22:195-207

https://doi.org/10.1016/0300-5712(94)90107-4

37. Deogade SC, Suresan V, Rathod JR, Naitam D. Prevalence and Impact of Dentine Hypersensitivity among Undergraduates in a University Campus of Central India. Ann Med Health Sci Res. 2017;7:137-43.

38. Ye W, Feng XP, Li R. The prevalence of dentine hypersensitivity in Chinese adults. J Oral Rehab, 2012;39:182-87. https://doi.org/10.1111/j.1365-2842.2011.02248.x

39. Taani DQ, Awartani F. Prevalence and distribution of dentine hypersensitivity and plaque in a dental hospital population. Quintessence Int 2001;32:372-76.

40. Rao A, Mitra D, Prabhakar AK, Soni S, Ahmed S, Arya S. The reduction efficacy of dentinal hypersensitivity by two commercially available desensitizing toothpastes: Vantej and Colgate Pro- Argin. Saudi Endod J 2014;4:7-12.

https://doi.org/10.4103/1658-5984.127980 